\title{
El lugar de la Revolución Rusa en los ciclos revolucionarios en América Latina
}

Resumen: La significación de la Revolución Rusa en la historia política latinoamericana no ha sido unívoca. Los estudios históricos han reconstruidosuinmediatarepercusión. Es sabido que la cartografía de las izquierdas en el subcontinente se modificó con el surgimiento de los partidos comunistas. Sin embargo, la relevancia de lo revolucionario no fue introducido en la historia latinoamericana por el acontecimiento soviético. En este trabajo se ensaya una ubicación de la relevancia de la Revolución Rusa en la historia latinoamericana y en los itinerarios revolucionarios del subcontinente.

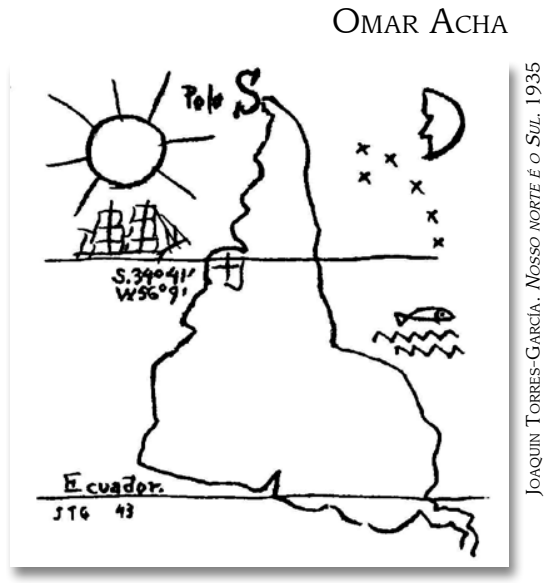

Palabras clave: Revoluciones. Revolución Rusa. América Latina. Izquierda.

\section{The Place of the Russian Revolution in the Revolutionary Cycles in Latin America}

Summary: The significance of the Russian Revolution in Latin American political history has not been unequivocal. Historical studies have rebuilt its immediate impact. It is known that the cartography of the left in the subcontinent was modified with the emergence of the communist parties. However, the relevance of the revolution was not introduced in Latin American history by the Soviet event. In this paper, we study the relevance of the Russian Revolution in Latin American history and the revolutionary itineraries of the subcontinent.

Doctor en Historia por la Universidad de Buenos Aires (UAB) y por la École des Hautes Études en Sciences Sociales (EHESS), en Francia. Investigador del Consejo Nacional de Investigaciones Científicas y Técnicas (CONICET) y del Centro de Investigaciones Filosóficas.

E-mail: omaracha@gmail.com.

Keywords: Revolutions. Russian Revolution. Latin America. Left.

$\begin{array}{r}\text { RECEBIDO 10.02.2017 } \\ \hline \text { APROVADO 115.04.2017 }\end{array}$




\section{INTRODUCCIÓN: HISTORIA Y TEORÍA DE LAS REVOLUCIONES}

El objetivo de este trabajo consiste en reflexionar sobre las derivas del concepto de revolución en la historia latinoamericana desde el encuadre conceptual de nuestro presente, y más precisamente, desde la ocasión brindada por la conmemoración de la Revolución Rusa.

El de la conmemoración es un género opaco, que concita talantes diferentes e incluso antagónicos. Pero aquí no se encontrará tanto una celebración ni una impugnación del proceso revolucionario como un análisis histórico-cultural de qué puede significar hoy pensar las repercusiones de la Revolución Rusa en el mediano plazo de historia latinoamericana.

En términos históricos, en efecto, todavía la "historia efectual" de la Revolución Rusa, es breve. Siguiendo al Gadamer de Verdad y método, la efectualidad histórica consiste en la interacción entre planos de experiencia heterogéneos, de pasados y presentes activos (GADAMER, 1988). El significado de lo revolucionario habrá todavía de cambiar a medida que los conflictos interpretativos diriman sentidos no fijados de antemano. Esos sentidos serán las resultantes polémicas, discutibles, de las divergencias mismas, pero también de las persistencias fastasmales con que el hecho revolucionario interroga una era aparentemente post-revolucionaria, aleccionada por los excesos, mesianismos, totalitarismos, relativismos, o una edad de la razón finalmente conquistada.

Intentaré pensar las respuestas atinentes a tres preguntas: ¿hay una secuencia de lo revolucionario en el subcontinente latinoamericano y qué lugar posee en ella la Revolución Rusa? ¿Continúa activa la interrogación por "la revolución" tras el cierre del ciclo histórico de la más influyente revolución ocurrida después de la Revolución Francesa? ¿Cuán moderna es la revolución en la actualidad de América Latina cuando se piensa que las revoluciones solo pueden ser postmodernas en un mundo postmoderno (definida esa postmodernidad por el ocaso del ciclo "soviético" de la práctica revolucionaria)? Las respuestas ensayadas a estas preguntas serán forzosamente esquemáticas. No podría suceder de otra manera. Pero estimo que no son inútiles si permiten establecer, 
justamente por su esquematismo, una visión de conjunto capaz de habilitar pensamientos diferentes a la reconstrucción monográfica de aconteceres intransferibles.

Por ejemplo, en su libro contra la "idea comunista" François Furet combatió "el embrujo universal de octubre", esto es, la universalización arbitraria de una experiencia específica como modelo generalizado de transformación revolucionaria en todo el globo. Furet recuperó la evaluación crítica de Bertrand Russell en un libro de 1921, donde el autor de The Practice and Theory of Bolchevism señalaba que "el bolchevismo es más aclamado en el extranjero que en su patria. En Rusia es un régimen odiado como una tiranía y fuera de Rusia es esperado como una liberación. Un fracaso en el orden de las realidades, acompañado por un éxito en el de las creencias" (FURET, 1995, p. 115-116). Así las cosas, una "creencia" devenida "idea" se expandió por el planeta sometiendo las experiencias particulares al mandato de una verdad que encontraba su sede inmarcesible en Moscú. La reconstrucción que seguiré aspira a mostrar que, justamente al contrario de lo que señala Furet, la impronta de la Revolución Rusa revela matizaciones y versiones sumamente complejas que espero destacar en el caso latinoamericano. Con todo, creo que posee una validez mayor, inasimilable a las lecturas simplificadas de ejercicios de "historia de las ideas" en que la complejidad de lo real es subsumida en el imperio de las creencias, y sobre todo de las consideradas peligrosas.

\section{LO REVOLUCIONARIO EN AMÉRICA LATINA}

Una primera indicación sobre la mencionada complejidad consiste en referir a la preexistencia de experiencias revolucionarias en el subcontinente, experiencias que no cesaron de entrecruzarse con la ostensible novedad de la Revolución Rusa, pero a cuyo influjo no se sometieron pasivamente.

Comienzo por referir a una influyente corriente interpretativa que subraya el carácter universal que acompañó al nacimiento histórico del concepto de revolución (KOSELLECK, 1993, p. 67-85; WILLIAMS, 2003, p. 286). En efecto, en el plano de la reconstrucción conceptual como el practicado por la historia intelectual, es 
plausible sostener que durante dos siglos la posibilidad histórica de la revolución -y por cierto no solo en América Latina-involucró una vertebración de alcance conceptual como contraparte de un proceso objetivo que hoy denominamos "mundo". No había revoluciones particulares, pues el "hacer la revolución" suponía una idea del pasado y una orientación, no importa lo incierta que fuera, del porvenir. Sobre todo hacia el inicio del siglo XIX se propusieron diferentes nociones para concebir esa unidad de lo real que hasta hacía pocas centurias era impensable en un plano puramente inmanente, terrenal. Sin embargo, en el orden de las prácticas las representaciones conceptuales constituyen solo un ámbito de las experiencias vividas.

Para lo que poco a poco, desde principios del siglo XX, comenzará a llamarse América Latina no es difícil percibir la dificultad con que se instaló la noción de revolución. Porque si el ciclo revolucionario abierto con la prisión de Fernando VII mezcló líneas conceptuales de distintos tiempos (el democratismo local español de larga data con la novedad revolucionaria francesa de la "voluntad del pueblo"), esa novedad fue vivida en las colonias americanas de la corona castellana como un derrumbe institucional que habilitó diferentes proyectos de qué hacer para reconstituir el poder. Fue un ciclo revolucionario porque emergieron pronto voluntades de una ruptura radical con el poder peninsular. Pero el proceso no surgió de una conciencia preexistente en busca de su expresión (HALPERIN DONGHI, 1985).

Ahora bien, estos límites históricos de una noción demasiado unívoca de revolución encontró muy pronto un matiz, digamos intra-conceptual, en su propio desarrollo institucional (pues la revolución fue un dispositivo en sentido foucaultiano en el que se ensamblaron discursos, prácticas, normativas, condiciones económicas). Durante el siglo XIX el concepto de revolución se constituyó como la contracara del concepto de historia, o al menos, la imagen de una historia nacional. La revolución triunfante involucraba la afirmación de una nación autónoma, delimitada generalmente a través de enfrentamientos bélicos que constreñían a la determinación de identidades. En los casos americanos la "invención de la nación" constituyó una secuencia compleja derivada 
del carácter abrupto del acontecer revolucionario. Es que para el paradigma romántico en que prosperó la nación, ella provenía de una historia "profunda". Conceptualmente, entonces el momento revolucionario estuvo lejos de constituir un corte unívoco con un pasado colonial con el que debía distanciarse para afirmar la integridad de la nueva nación.

La fractura colonial y la multiplicación de naciones postcoloniales profundamente escindidas por las distancias, la sedimentación de numerosas historias incorporadas al imperio español (su par lusitano siguió un recorrido diferente por la persistencia de la forma monárquica del poder), ${ }^{1}$ imprimió peculiaridades a las revoluciones latinoamericanas. Todavía hoy las historiografías más desarrolladas se preguntan por las eficacias de las revoluciones Norteamericana y Francesa en el ciclo "atlántico" de las revoluciones. Se hace crecientemente firme la convicción de que pensar las revoluciones independentistas como un reflejo de otras revoluciones ejemplares empobrece su tema. Por otra parte, se torna cada vez más sólido el consenso sobre la coexistencia de un ciclo atlántico de la revolución con sus formas específicas. Basta pensar en el caso de la revolución en Haití para "provincializar" las pretensiones universales atribuidas, según los diversos análisis, a las revoluciones de Estados Unidos o Francia. ${ }^{2}$

La difícil pero finalmente exitosa constitución de los Estados nacionales a lo largo del siglo XIX condujo a un apagamiento del hecho revolucionario en beneficio de las pugnas particulares en la formación de nuevos Estados. Sin embargo, pronto la decidida inserción de las economías nacionales en el mercado mundial capitalista, entre cuyos aspectos se cuentan masivos movimientos poblacionales entre Europa, Asia y América, despertaron un nuevo impulso de lo revolucionario. Con los claros matices de las situaciones nacionales, hacia el año 1900 la idea revolucionaria resurgió en América Latina en un molde complejo donde el anarquismo y el socialismo (este pronto escindido entre una variante

1 Sin embargo, el caso brasileño tuvo varias conexiones con las revoluciones que recorrieron el resto del subcontinente (PIMENTA, 2006).

2 Sobre Haití y sus interpretaciones, ver JAMES (2003) y TROUILLOT (1995). 
reformista y el sindicalismo revolucionario) compitieron por ser la expresión de un cambio social profundo. Aunque en ningún caso constituyeron peligros sustantivos para el Estado, el temor a la posibilidad revolucionaria se modificó bruscamente luego de 1917 con la novedad rusa.

Esto no significa que las experiencias históricas se redujesen al avance de las ideologías radicalizadas europeas, tal como gustaron afirmar los sectores dominantes al menos desde la Comuna parisina de 1871. Basta incorporar un acontecimiento de enorme influencia continental como la Revolución Mexicana iniciada en 1910 para desmentir el carácter heterónomo del resurgir de lo revolucionario en el subcontinente. Volveré sobre el tema mexicano pues concita varios motivos en la reflexión latinoamericana sobre la revolución social. Con todo, el advenimiento de la Revolución Rusa en el contexto de una crisis de Occidente revelada por la Gran Guerra, impuso un parteaguas histórico irreversible.

El pasado de revoluciones de la independencia mantuvo su relevancia a pesar del mencionado parteaguas. Las menciones muy rápidas de Haití y México, cada una con dificultades extraordinarias, conduce a intersectar la aproximación conceptual a la historia de las revoluciones con sus implantaciones situadas. Pero ciertamente no a intentar sustraer la historia política e ideológica latinoamericana, sobre todo por supuesto a sus vertientes de izquierdas, del torrente histórico del acontecimiento ruso.

El contexto histórico de la revolución soviética fue tan importante que pudo - incluso cuando se impuso la idea estalinista del "socialismo en un solo país"- abandonar su sitio de nacimiento. De Eurasia pasó al resto del mundo, transformándose, más allá de las propias aspiraciones bolcheviques a su universalización.

Sucede que las condiciones de la expansión de la revolución modificaron su alcance y perspectivas. El hecho revolucionario, que para los bolcheviques solo podía triunfar si devenía "mundial", adoptó formas y variedades múltiples. Desde aproximadamente 1922-1923 en Europa se produjo un cambio de tendencia político-cultural que neutralizó las fuerzas revolucionarias, las venció y las aisló. En América Latina la cadencia fue distinta, pero también convergente. La reactivación de las protestas obreras y 
campesinas hacia el fin de la Gran Guerra europea, la aparición de opciones políticas revolucionarias o la escisión de las formaciones de izquierdas en una orientación de ruptura revolucionaria, se fueron apagando hacia inicios de la década de 1920. En algunos países por la represión pero sobre todo por la aparición de gobiernos con mayor inclinación a la reforma (como en la Argentina), la estabilización de procesos de transformación social intenso (como en México), o la aparición de primeras experiencias autoritarias (como en Perú), el saldo fue que durante las décadas de 1920 y 1930 el eco revolucionario en el subcontinente se encontró severamente cuestionado. ${ }^{3} \mathrm{Al}$ mismo tiempo se expandió un creciente impulso de un nacionalismo de nuevo cuño, también él influido por orientaciones similares europeas (el reciente fascismo y el Acción Francesa fueron los fenómenos más notorios), un impulso que no dejó incólumes a las izquierdas.

Otra vez, es preciso prevenirnos contra una imagen solo especular de tendencias europeas. Signo de ello es la fuerza que en varios países latinoamericanos en esa misma época adquirieron los indigenismos en la imaginación revolucionaria y en la propia disputa por el significado de la revolución.

El APRA peruano fue el antecedente más revelador del entrecruzamiento de la proyección revolucionaria con el tema nacional y sus residuos postcoloniales. La historización de la revolución en América Latina luego del parteaguas soviético no concluyó allí. Con la generación de las propuestas políticas populistas, grosso modo entre 1930 y 1975, se planteó una ecuación de la "revolución nacional" donde la relevancia de las izquierdas anticapitalistas fue puesta en cuestión. La geografía de la revolución entonces se modificó, reinventándose en lo que después de la Conferencia de Bandung (1955) se denominó el "Tercer Mundo". Ya en este momento la significación universal de la Revolución Rusa en América Latina estaba severamente dañada. Más que una brújula de la revolución, 1917 había dejado paso a la Unión Soviética como un actor de primer orden en la geopolítica planetaria.

3 Sin embargo, incidencias pro-revolucionarias se desarrollan en los primeros años treinta en Chile y Cuba. 
Desde 1959 la Revolución Cubana ofreció un nuevo envite para un ciclo subcontinental sin el cual no se comprende el aliento contrarrevolucionario de las dictaduras latinoamericanas, es cierto que antecedidas por el golpe contra Jacobo Arbenz en la Guatemala de 1954. En todo caso, treinta años más tarde la revolución social perdió credibilidad como orientación política en todo el planeta. 1989 quiso ser así la tumba de lo revolucionario. La ruptura histórica se produjo en las posiciones políticas y en las categorías intelectuales. Fueron los años del imperio del postmodernismo, de la diferencia y la multiplicidad, del cuestionamiento de los "grandes relatos", entre los cuales estaba el de Revolución.

Pienso que la problemática de la revolución en América Latina -aquí tan rápidamente sintetizada- es un punto de vista útil para dar cuenta de la circunstancia del centenario de la Revolución Rusa. Sin desmedro de lo antes esquematizado, y en contraste con una prolongada tradición argumentativa cultivada por diversas corrientes ideológicas, la Revolución Rusa no fue una fuerza histórica radicalmente ajena e irrelevante para una América Latina que pertenecería a un orden cultural propio. No lo fue durante las siete décadas de su existencia y no lo es hoy que meditamos sobre su posterioridad.

\section{LA REVOLUCIÓN, DE AYER A HOY}

Los años setenta y los sucesos posteriores a 1989 en los llamados "socialismos reales" de Europa y Asia suscitaron la convicción de un fin de época para la política revolucionaria. Sus términos clásicos, sobre todo en sede marxista, parecieron declinar en su relevancia teórica y, sobre todo, política. En América Latina el viraje ideológico fue previo, aunque la convicción en ciertas fracciones de las izquierdas sobre la defensa "incondicional" de la Revolución Cubana creó una zona de disputa e indecisión. En todo caso, las polémicas sobre las actitudes de las izquierdas hacia Cuba no modificaron un panorama ideológico de tendencias inequívocas.

La sensibilidad anti-revolucionaria que legó el ciclo de la represión militar en todo el subcontinente latinoamericano, de 1964 a 1990, redujo bruscamente el interés por las transformaciones 
profundas e incluso su credibilidad. Esto no se explica sólo por la radicalidad de la represión, sino también por las dificultades internas de las estrategias revolucionarias de la época. La estrategia revolucionaria fue vencida y fracasó. Su reconstrucción no podía entonces en rearmarse tras la derrota para acometer con mejores pertrechos la misma tarea.

Las opciones políticas radicales perdieron vigencia. En el plano intelectual, las ciencias sociales y las humanidades se volcaron a los temas de la ciudadanía, la gobernabilidad y la democracia. La política radical se hizo posibilista y en algunos casos sistémica (el ejemplo paradigmático es el de Fernando Henrique Cardoso en el Brasil). Incluso aquellos movimientos nacionalistas que reivindicaron en algún momento una versión autóctona de la revolución, como el PRI mexicano o el MNR boliviano, pasaron a gestionar el Estado bajo los cánones neoliberales.

En ese orden de cosas, la revolución pasó a ser un "imaginario" que había capturado a sus partidarios, encegueciéndolos ante la incertidumbre pluralista de la democracia, lanzándolos al mesianismo violento de lo totalitario. Como señalé antes, ese viraje ideológico fue global. La calificación de la revolución como desastre afectó pronto a la que fue durante varias décadas el caso por excelencia, la Revolución Rusa, representada por Orlando Figes a mediados de los Noventa europeos como "la tragedia de un pueblo" (FIGES, 2000). ¿Cómo exceder ese espíritu anti-revolucionario que descubre entre los pliegues de la revolución la semilla inexorable, aunque su emergencia fuera contingente, del desastre?

Un primer movimiento consiste en realizar un arqueo de los legados del pasado. La historia política latinoamericana produjo diversas prácticas y conceptos de revolución, cuyos rasgos principales -la irresolución entre el sustantivismo nacional y el molde universal de las revoluciones ejemplares, la búsqueda de caminos específicos para las revoluciones locales- se han enunciado páginas arriba. Las investigaciones dedicadas a representar las revoluciones, sin embargo, avanzaron tímidamente sobre una periodización, tipología y cartografía de los procesos revolucionarios. El objetivo de esta sección consiste en proveer una periodización una vez establecido que la naturaleza y alcance de lo revolucionario 
jamás han sido iguales a sí mismas, nunca se sustrajeron a la historicidad.

No obstante, los estudios sociales con frecuencia postularon una idea de revolución aplicable al conjunto del subcontinente. O más exactamente, oscilaron entre una fenomenología de revoluciones sin inquirir por su estructura y una continuidad de la serie revolucionaria. Este problema dañó a numerosas reconstrucciones históricas. Menciono casi al azar los libros del colombiano Orlando Fals Borda, Las revoluciones inconclusas en América Latina, y del chileno Fernando Mires, La rebelión permanente. Las revoluciones sociales en América Latina, como prototipos de textos en los que se puede seguir una cadena de sucesos revolucionarios sin una detenida elaboración conceptual y sin la distinción de singularidades históricas (FALS BORDA, 1970; MIRES, 1988). En ellos no se diferencia entre fases o situaciones epocalmente heterogéneas, desafiantes para una matriz interpretativa demasiado compacta. Los análisis de caso más sofisticados han sido propuestos por estudiosos académicos aunque aquellos no hayan dado lugar a una historia general de las revoluciones en América Latina. El reciente latinoamericaniso se inclina por los estudios particulares aún cuando se los inscribe en un formato de libro sobre "las revoluciones" (GRANDIN; JOSEPH, 2010).

Hoy es inviable presentar una senda homogénea de lo revolucionario en la historia latinoamericana, una sucesión de muestras reveladoras de la continuidad insurrecta de un subcontinente en perpetua contestación. Sí podemos, en cambio, definir "eras" de las tendencias revolucionarias, "periodos" con una serie de rasgos característicos, regímenes de causas o de resultados, concordancias o divergencias moduladas regionalmente.

Sin la posibilidad de ingresar a un debate minucioso sobre dichos periodos, indico la heterogeneidad detectable entre el segmento 1780-1902, que es el de los procesos revolucionarios independentistas de las dominaciones coloniales, del segmento que transcurre entre 1910 y 1979 con revoluciones sociales en las que se dirime la difícil relación entre los proyectos nacionalistas y los socialistas (sobre esta última cuestión, KNIGHT, 1990). En el 
centro de este segundo segmento el mayor relieve le corresponde a la Revolución Cubana.

El primer ciclo comienza con las rebeliones de los años 17801781 asociadas a los nombres de Túpac Amaru, Tomás Catari y Túpac Catari, ellas mismas pre-revolucionarias pero nutrientes decisivas de un proceso de movilización de mediana duración con importantes efectos posteriores. Continuaron una senda de movilización de larga duración en la que se comprende la emergencia de las revoluciones de la independencia, no como fenómenos deducibles de dicha movilización, sino como ambiente fermentado en el que se inscriben los sucesos políticos-institucionales. En este sentido no se puede discrepar con el reproche de Sidney Tarrow contra el privilegio del estudio comparativo de las "grandes revoluciones" en detrimento de otras luchas y movimientos sociales y culturales sin los que dichas revoluciones resultan abstracciones. Esto, dice Tarrow, "ha desperdiciado la posibilidad de comparar las revoluciones con conflagraciones menores, haciendo que sea imposible aislar qué factores de la dinámica de un ciclo de protestas lo llevan por el camino de la revolución y cuáles lo llevan al colapso" (TARROW, 1997, p. 61).

El ciclo adopta un cariz nítido con las revoluciones de la independencia desencadenadas en el bienio 1804-1810 y llega hasta la emancipación nacional de Cuba en 1902. En ese primer ciclo hay una sorpresa formidable: se produce la primera revolución social en América Latina con el proceso de subversión y construcción de poder autónomo de la población negra en lo que pasaría a denominarse Haití. Este tramo no fue, por ende, homogéneo. Su perfil adopta una figura convincente de modo retrospectivo tras la experiencia histórica del siglo veinte.

El segundo ciclo se inicia con la revolución en México desde 1910 y encuentra su última expresión decisiva en el triunfo revolucionario en Nicaragua (1979). Aquí encuentra su lugar la significación global de la Revolución Rusa y la tensión "socialista" que desde entonces adquirió el hecho revolucionario incluso si sus alcances y resultados fueron muy ajenos a una modificación de las relaciones sociales de producción. Un poco más abajo me detendré sobre el tema. Por el momento señalo que las diferencias 
básicas en las condiciones histórico-materiales de cada etapa: en la primera (circa 1780-1860), las formaciones sociales coloniales y postcoloniales contaban con mercados internos débiles y estados ínfimos, sin espacialidades definidas, las clases sociales (más precisamente debería hablarse de una multiplicidad de castas y grupos atenidos a diversas categorizaciones sociales poco a poco reorganizadas por el lento desarrollo del capital) y las ideologías eran porosas; en la segunda (circa 1860-1979) el capitalismo se encuentra en proceso de consolidación orientada a la exportación de producción primaria y las clases, aunque en flujo, han cuajado y tienden a organizarse, mientra el Estado ha desarrollado un aparato considerable de administración y represión.

Esquematizando un pasado complejo, podemos distinguir dos perspectivas divergentes en el segundo ciclo de las revoluciones. Por un lado, una posición que evalúa las herencias coloniales y la subordinación imperialista como justificadoras de una revolución nacional, o democrático-burguesa, según la cual lo revolucionario involucra el desarrollo de una fase capitalista en lo económico y liberal en lo político; el nacionalismo revolucionario se inclina a fórmulas políticas antiliberales en ambos órdenes. En esta estrategia gradualista se amparan ideologías tan distintas como el nacionalismo revolucionario, el populismo y el socialismo reformista, así como el comunismo de corte estalinista. Por otro lado, una posición en la cual la definición capitalista de las formaciones económico-sociales predominantes orienta la estrategia hacia metas socialistas más o menos inmediatas, pues la evaluación de los límites de las burguesías locales para propender al progreso social y político implica el reemplazo de su función histórica revolucionaria por la clase obrera, según las circunstancias, aliada con el campesinado o la pequeña burguesía. Aquí podemos ubicar a los programas políticos trotskistas y guevaristas. Durante todo el siglo XX, la revolución en América Latina dirimió sus posibilidades entre ambas veredas, aunque no siempre fueron opciones enfrentadas. Con temporalidades muy diversas, con la excepción del nacionalismo revolucionario todas las estrategias intentaron articular la "liberación nacional" con la "revolución social". 
El advenimiento de la Revolución Rusa, y sobre todo su repercusión en los escenarios político-culturales latinoamericanos, ocasionó una mutación en el tablero de las ofertas transformadoras en las izquierdas e incidió en la configuración el entero espectro ideológico. Como por ejemplo ha mostrado recientemente Roberto Pittaluga a propósito de las izquierdas en la Argentina, la "recepción" de la novedad soviética suscitó diferentes actitudes, movilizó distintas interpretaciones y se inscribió en un escenario ya complejo (PITTALUGA, 2015).

Lo que a la vez generó puede ser sintetizado de la siguiente manera. En primer término instaló un nuevo centro de gravedad para las discusiones en y entre las izquierdas. La determinación de qué es la izquierda y cuáles son sus atributos ya no fue la misma tras la ocurrencia de la Revolución Rusa. Todas las variantes preexistentes de las izquierdas se dividieron al respecto, construyeron sus versiones y las conectaron de maneras diversas con los itinerarios ideológicos previos. La consolidación del poder bolchevique tras el fin de la guerra civil y el desarrollo de una organización internacional vigorosamente hegemonizada por la dirigencia rusa, difundió una idea normativa de la revolución. La misma debía atenerse a los modelos establecidos en los "periodos" estratégicos de la Internacional. Una convicción común a las izquierdas en torno al combate mundial por una transformación incapaz de triunfar en los arbitrarios espacios nacionales devino en una tendencia a imponer una vía privilegiada para la revolución. En el plano conceptual, tuvo un efecto negativo cuando impuso una visión de la verdadera revolución identificada con la Revolución Rusa, pues en contraste con ella las revoluciones en América Latina tendieron a ser vistas como incompletas, inacabadas, traicionadas, congeladas, etcétera. ${ }^{4}$

4 Pienso, entre numerosos ejemplos, en los escritos de Adolfo Gilly sobre la Revolución Mexicana o de Liborio Justo sobre Bolivia en 1952 (GILLY, 1971; JUSTO, 2007). 


\section{EL PROBLEMA DE UNA VÍA REVOLUCIONARIA PRIVILEGIADA}

A contramano de las impugnaciones excesivamente generalizadoras sobre el carácter mesiánico, extremo y totalista del "imaginario de la revolución", una revisión de los discursos y prácticas revolucionarios en América Latina (y sin duda no solo allí) revela las incertidumbres que habitaron a las estrategias revolucionarias por parte de las izquierdas. No debemos olvidar que entonces, antes de la delimitación nacionalista impuesta en las décadas de 1920 y 1930, el alcance y circulación de ideas y activismos era global. En las izquierdas, el debate se tornó más agudo cuando la Unión Soviética promovió la Tercera Internacional con un programa revolucionario mundial que contenía una fórmula para los países periféricos (CABALLERO, 1987). La estrategia de un andamiaje revolucionario internacional o adecuado a un conjunto latinoamericano en modo alguno inhibió la emergencia de álgidos desacuerdos en el seno de las izquierdas, situadas en recortes nacionales o macrorregionales, incongruentes con las fórmulas genéricas. Así aconteció en el Brasil, donde las peculiaridades históricas del gigantesco país impusieron temas relativos a una "revolución brasileña" irreductible a una latinoamericanidad por entonces un tanto abstracta (ROIO, 2000).

Esta determinación de una figura universal de la revolución debe gran parte de su fuerza a la lógica universalizante que la dirigencia bolchevique impulsó tras la constitución de la Tercera Internacional y la "bolchevización" de los partidos comunistas. Es importante subrayar que esa universalización fue el resultado de la conjugación de fuerzas históricas y no una premisa de tales fuerzas. Todavía durante los años 1920 socialdemócratas como Karl Kautsky en Europa y Juan B. Justo en América Latina denegaban la validez universal que se autoatribuía un movimiento comunista en difícil pero inocultable crecimiento. El modo en que la presencia de un poder revolucionario identificado con la Revolución Rusa adquirió efectividad en el subcontinente latinoamericano lidió con las diferencias internas a las situaciones locales. En otras palabras, la pujante presencia de "la revolución" hizo que la necesidad de confrontar con ella condujese, antes que a la sumisión hacia 
su carácter modélico, a la interrogación de qué carácter tendría la revolución en cada país latinoamericano.

Dentro de la misma compulsión a la adecuación histórica con una revolución triunfante, por ejemplo, el debate entre Víctor Raúl Haya de la Torre y José Carlos Mariátegui en el Perú de mediados de la década de 1920 estableció la urdimbre de un diferendo estratégico que se reiteraría, con las cadencias propias de las condiciones locales, en distintos momentos y países latinoamericanos. Mientras para Mariátegui las contrariedades irresueltas por la independencia y el desarrollo socio-económico exigían una revolución socialista que liderada por la clase obrera y el campesinado indígena eliminara las relaciones sociales feudales, Haya de la Torre sostuvo que la revolución debía conducir a un capitalismo progresivo que preparara las condiciones para el socialismo en el futuro distante. En esa tarea se fundamentó el programa del APRA, de tanta significación para comprender los entresijos de los debates sobre la revolución en América Latina.

La polémica de Haya de la Torre se dirigió contra lo que consideraba un europeísmo mariateguiano, invisibilizador de la situación de dominio imperialista que oprimía al Perú. Es que, según Haya, en América Latina era inviable aplicar sin cambios la idea universal de la revolución comunista. Era necesario considerar las singularidades históricas, con una derivación muy distinta a la del "ni calco ni copia" del autor de los Siete ensayos. En efecto, las concepciones de tiempo y espacio, y las regularidades de la vida misma, en "Indoamérica", eran diferentes y demandaban, por lo tanto, una práctica revolucionaria intransferible (MARIÁTEGUI, 1979; HAYA DE LA TORRE, 1936).

Una argumentación similar fue propuesta por el argentino Jorge Abelardo Ramos en su agria discusión con las izquierdas "cipayas" (las socialistas reformistas y las comunistas pro-Moscú) que habían rechazado al peronismo como instancia de "revolución nacional" son la cual la revolución "socialista" devenía una entelequia. De acuerdo al argumento de Ramos, tanto Lenin como Trostky afirmaron que en un país semicolonial -tal sería el caso de todos los estados nacionales latinoamericanos- la izquierda marxista, sin ceder en la independencia organizativa e ideológica del partido 
obrero, debía apoyar "críticamente" los programas burgueses progresistas y antiimperialistas. Sólo en un futuro indeterminado se plantearía la oportunidad de una revolución socialista. De otra manera, se actuaba objetivamente en favor de las potencias imperiales y sus aliados locales que atacaban a los proyectos nacionalistas de corte mercado- internista. Eso era lo que explicaría la asociación de las viejas izquierdas con los sectores reaccionarios y pro norteamericanos en el caso de la Argentina de Juan Perón o la Bolivia de Gualberto Villarruel. La fórmula estratégica constituía una adaptación local del marxismo, devenido entonces marxismo criollo o latinoamericano (RAMOS, 1973).

La tradición de la izquierda nacional que comprende entre otros a Haya de la Torre y Ramos no fue la única que procuró una nacionalización de la revolución. No obstante, la izquierda nacional estaba habitada por una contradicción con la afirmación de una "nación latinoamericana" reprimida por los imperios: ¿la revolución argentina o mexicana eran estructuralmente la misma cosa que la boliviana o la venezolana? ¿No implica esta equiparación una simplificación inconveniente de las situaciones específicas? Este tipo de preguntas quedó informulado debido a la preeminencia de un sistema de dominación común a toda la "nación latinoamericana", forjada por la coalición del imperialismo, las oligarquías traidoras y el colaboracionismo de las izquierdas "cipayas".

Salvo en sectores convencidos del carácter universal de la revolución, también entre quienes se situaban desde la perspectiva de una estrategia socialista inmediata se observa una tensión de adaptación al contexto latinoamericano. Es conocido el punto de vista del contendiente de Haya, Mariátegui, suficientemente tratado en la bibliografía de las ciencias sociales como para exigir una presentación aquí. Bastará con indicar que para Mariátegui la hegemonía programática de la clase obrera no implicaba la negación de la importancia de la otras clases subalternas en la realidad nacional. Por el contrario, la relevancia reconocida al campesinado indígena modificó la imaginación histórica de las tradiciones y mitos que insuflarían energía pero también dirección en la 
construcción socialista a la revolución "indoamericana". ${ }^{5}$ El propio Mariátegui creyó encontrar allí el fundamento de una estrategia continental diversa a la defendida por la Tercera Internacional de hegemonía estalinista (FLORES GALINDO, 1980).

Quizá no haya una propuesta de revolución pensada para América Latina que gozara de la capacidad de expansividad como la elaborada por Ernesto "Che" Guevara. La repercusión del "castroguevarismo" se comprende en la profunda conmoción generada por el devenir socialista de la Revolución Cubana, que a pesar de su alianza asimétrica con la Unión Soviética constituyó para fracciones de la izquierda política en tierras latinoamericanas un modelo de práctica revolucionaria. Según subraya Michael Löwy, Guevara fue más que un guerrillero heroico: propuso una perspectiva de la lucha revolucionaria especialmente pensada para las situaciones del subcontinente (LÖWY, 1971). Las contribuciones de Guevara conciernen al período revolucionario y al postrevolucionario. Interesa sobre todo el primer tramo de su pensamiento político de la revolución. El razonamiento principal concernió a la factibilidad de la transformación social en los escenarios latinoamericanas, caracterizados por gobiernos dictatoriales cómplices de la subordinación imperialista. Esta delimitación señala sin duda un confín del planteo guevariano, poco útil para dar cuenta de las situaciones democráticas de hegemonía burguesa. En la misma dirección, registro que la sociedad revolucionaria pensada por Guevara no fue la de tipo urbano con altas concentraciones industriales. Fue la prevalecientemente rural, con una amplia diseminación de poblados cercanos a las sierras o zonas boscosas. En esta historización y espacialización de la estrategia revolucionaria se advierte, para lo que aquí importa, la relavitización de la Revolución Rusa como modelo de transformación.

5 Cf. Quijano (1982). Subrayemos que la noción mariateguiana de revolución tenía una relación ambivalente respecto de la reducción modernizante del evento transformador. Este no sólo apuntaba a un futuro incontaminado por un pasado sin valor. Mariátegui impugnó el privilegio del presente y del futuro en la filosofía de la historia de la izquierda marxista al recuperar el valor mítico y organizacional de las comunidades originarias. 
Es que desde el fin de la Segunda Guerra Mundial se modificó la "historia efectual" de la Revolución Rusa en América Latina, cuya significación fue reemplazada por la geopolítica global donde la Unión Soviética constituyó un antagonista y competidor frente al avasallante poderío norteamericano. Para entonces la Tercera Internacional había dejado de existir (Stalin decidió su disolución en 1943) y la defensa de la "Patria del socialismo" pasó a ser la clave política de los partidos comunistas latinoamericanos.

De las características de la revolución pensadas por Guevara a partir de condiciones específicas se derivó un "guevarismo". Esta es, desde luego, una afirmación que exige un desarrollo mayor que aquí no puede ser realizado. Lo que revela la misma importancia del guevarismo en América Latina es la caída definitiva definitiva de la Revolución Rusa como modelo revolucionario, salvo para algunos grupos comunistas de la línea estalinista y del trotskismo anti-estalinista. La Revolución Rusa resistió en su validez normativa entre quienes disputaban el legado del leninismo. En cambio, para los sectores ligados a lo que en América Latina se reconoció o fue reconocido como "nueva izquierda", aquella validez estuvo siempre en cuestión.

\section{5 ¿QUÉ RUINAS DE LA REVOLUCIÓN RUSA?}

Hasta aquí he considerado el tema de la Revolución Rusa dentro de un arco histórico mayor, relativo a un más heterogéneo itinerario de la revolución en América Latina. Su lugar en ese itinerario es decisivo pero en modo alguno permite comprender las peripecias de la revolución en el subcontinente. De tales peripecias he propuesto un recorrido esquemático de sus ciclos históricos, y he destacado que la enorme influencia del acontecimiento soviético fue multívoco, discutido y decayó como modelo revolucionario en las izquierdas latinoamericanas -con algunas excepciones- hacia 1960. Eso no obstó para que el derrumbe de la bloque del Este entre 1989 y 1991 fuera utilizado como una prueba definitiva del fracaso a priori de toda política revolucionaria.

Ahora bien, ¿qué persiste de este centenario de una Revolución Rusa de efectos tan diversos? Pienso que responder a esa pregunta 
requiere encarar una referencia teórica y otra de mayor precisión empírica (a esta aludiré más tarde). La teórica es necesariamente global pues una evaluación del legado de la Revolución Rusa es "universal". Así como fue universal su eficacia en reconfigurar el orden político-ideológico mundial, lo es también en el cierre de su ciclo histórico. Esa universalidad obtenida en su caída posee efectos paradójicos en un momento en que la generalidad ha sido cuestionada como vestigio de una modernidad igualmente abolida. En efecto, no es difícil adivinar un saldo del acontecimiento soviético en las teorías más recientes que en ese contexto han propuesto reinscribir la revolución en la agenda intelectual. Basta mencionar los usos de la revolución en autores como John Holloway, Antonio Negri o incluso Alain Badiou, para percibir la ruptura con el paradigma de la revolución sedimentado entre el ciclo atlántico de la revolución y la Revolución Rusa.

La versión "postmoderna" de la revolución contraría a la adopción "moderna" de un corte absoluto con el pasado como el rasgo principal del proceso revolucionario. La política radical postmoderna no rechaza la noción de revolución, a pesar de que desconfíe de sus orígenes "modernos". Es refractaria a la convicción típicamente moderna de que la revolución supone una fractura vertiginosa e indeleble entre el pasado y el futuro. En cambio, la revolución postmoderna implicaría una estrategia de "radicalización de la democracia", en la cual no hay un sujeto privilegiado, teleológicamente destinado a consumar la Historia. Tampoco halla en el Estado el núcleo del poder dominante a destruir, ni un "Estado revolucionario" es el ariete de la nueva sociedad por edificar. Más que en las contradicciones económicas, la revolución postmoderna quiere asentarse en la constitución de hegemonías políticas. No es que niegue la importancia de las desigualdades económico-sociales; sólo afirma que ellas no producen automáticamente concepciones ideológicas emancipatorias. En lugar de los partidos revolucionarios centralizados, propugna la autonomía de los movimientos sociales o los sectores excluidos. Obviamente, la perspectiva postmoderna define un debate con las diversas formas del marxismo tradicional, considerado como expresión típicamente moderna de la crítica y la revolución. 
Es cierto que el marxismo es una formación teórico-política moderna, incluso si aspira a una "post"-"modernidad" no capitalista. ¿Qué significa lo moderno del marxismo y su programa socialista? Simplemente que (1) implica un corte absoluto entre pasado y presente, (2) introduce una idea de formación social radicalmente nueva y progresiva, y (3) es consumada por un sujeto dialécticamente predeterminado por la estructura para ser su enterrador. A pesar del matiz introducido por el período transicional del socialismo, la revolución marxista sería catastrofista. El cambio real encarnaría un tajo abismal. Su modelo inexhausto sería 1789 y luego 1917. En esencia, la revolución del marxismo -cuya figura central es la Revolución Rusa- descendería directamente del jacobinismo.

Para la percepción postmodernista, la revolución debería adaptarse al largo plazo, a la constitución de una hegemonía política y cultural en la sociedad civil, a veces filiada en los planteos de Antonio Gramsci, o alternativamente desde el campo de "la multitud". El modelo de la revolución como conquista del poder estatal, en la figura de un golpe de Estado, tendría que ser resignado a favor de una lucha hegemónica más prolongada que instituyese una nueva subjetividad. Una visión alternativa, quizás más "postmoderna" que la versión recién expuesta es la que involucra una apuesta más autonomista, en la que se advierte el rechazo del ciclo soviético donde el Estado y el líder encarnaron el sentido de lo revolucionario. ${ }^{6}$

Según dije antes, existe otro encuadre más cercano y empírico para resituar el tema de la revolución en América Latina ante el cierre del ciclo histórico de la Revolución Rusa. Es imposible dar cuenta aquí de la complejidad de un fenómeno aún no concluido y sus resonancias para la noción de revolución en el subcontinente y más precisamente en América del Sur: las experiencias políticas y soiales vinculadas con lo que se han denominado como "gobiernos progresistas" durante los últimos quince años.

6 Un buen compendio de las orientaciones postmodernas de la revolución en Foran (2003). 
En Venezuela, Ecuador y Bolivia se ha hablado, desde una sede estatal conquistada a través de la democracia electoral, de nuevas revoluciones. Incluso en el caso de la Venezuela chavista se propuso la fórmula de un "socialismo del siglo XXI", en la que puede advertirse tanto el recurso a un significante del siglo precedente como la voluntad de plantear una enfática renovación. La experiencia zapatista en el sur mexicano, que no pretendió extenderse al orden nacional, fue opacada por una corriente que encontró variados entusiasmos dentro y fuera de América Latina. Esas experiencias se vieron pronto tensionadas por los límites que la estructura económica extractivista impuso, cuando cayeron los precios internacionales de las commodities que sostenían la intervención estatal, por la emergencia de oposiciones intransigentes en la sociedad civil y política, y por la ausencia de una movilización popular capaz de intervenir en una ruptura que cuestionase radicalmente las relaciones sociales políticas y económicas. Es demasiado pronto para dar por cerrado el significado y herencia de ese ciclo "progresista". Lo cierto es que en todas ellas el legado de una Revolución Rusa parece haberse disuelto incluso como referencia lejana. El más radical de los líderes populares del periodo, Hugo Chávez, manifestó alguna vez su interés por lecturas del marxismo (en particular de Trotsky), pero indudablemente esa inquietud no construyó una identidad con un acontecimiento soviético vivenciado como pretérito.

Denostados por un uso demasiado genérico del término "populismo", esas experiencias políticas sudamericanas encontraron en el bolivarianismo chavista una proyección latinoamericana deseada que no prosperó. Por demasiadas buenas razones, entre las que se encuentran tanto la intangibilidad de las estructuras nacionales como las restricciones para establecer una Alianza (el ALBA) con marcos particulares intactos. En ese sentido el convencimiento del bolchevismo marxista vigente en la Revolución Rusa, sobre que un desafío al dominio global del capital solo puede global, sobrevive entre las ruinas de su aparente defunción. 


\section{CONSIDERACIONES CONCLUSIVAS}

En este artículo he querido reflexionar histórica y teóricamente sobre qué puede decirnos hoy la Revolución Rusa para pensar las experiencias y prácticas revolucionarias en América Latina. He evadido voluntariamente el muy válido expediente de indagar las repercusiones fácticas de la Revolución Rusa, por ejemplo, en una agrupación política o en un conjunto de publicaciones periódicas de uno o más países del subcontinente. ¿Por qué? No porque me parezca un ejercicio improductivo o poco interesante, sino porque la opción elegida habilita cuestiones informulables desde un estudio monográfico.

He destacado la pre-existencia de la revolución como hecho histórico en América Latina, una idea del cambio radical que no fue introducida subrepticiamente por agentes foráneos que conspiraron contra la integridad nacional. La dinámica revolucionaria fue constitutiva del surgimiento de los nuevos Estados-nacionales latinoamericanos a lo largo del siglo XIX. Esas revoluciones fueron más políticas que sociales, y no aspiraron, como en algunas estrategias del siglo XX, a modificar las relaciones socio-económicas. Pero fueron al mismo tiempo profundas pues las jerarquías ya no fueron las mismas, a tal punto que numerosos agentes históricos concibieron el cambio como efectivamente revolucionario. Sin duda las revoluciones independentistas contuvieron matices sociales, pero no fueron generadas por la sedimentación de transformaciones que luego eclosionaron políticamente. Por el contrario, ocurrido el derrumbe de los poderes coloniales, se desplegaron en la búsqueda de un nuevo poder político. Fue el desarrollo de las nuevas formaciones sociales capitalistas a lo largo de la segunda mitad del siglo XIX el que generó las condiciones para un nuevo ciclo revolucionario.

El siglo XX latinoamericano comenzó su itinerario revolucionario con una Revolución Mexicana que no fue universalizada . El modelo revolucionario se presentó con la Revolución Rusa de 1917. Pero incluso entonces las recepciones latinoamericanas de dicha revolución negociaron su validez con las situaciones locales, con las tradiciones ideológicas y las relaciones de fuerza sociales y políticas existentes. He denominado a esas recepciones como 
un "parteaguas", sobre todo para las estrategias de las izquierdas, las que se vieron severamente interpeladas por una revolución triunfante.

Sin embargo, el nacionalismo, el surgimiento de los movimientos populistas, el contexto de una Unión Soviética estalinizada y la Guerra Fría crearon un marco en el cual la validez universal que desde el bolchevismo quiso tener la Revolución Rusa se vio atenuada por las circunstancias específicas de cada espacio nacional latinoamericano. Cuando aconteció la Revolución Cubana, que ciertamente puede ser puesta en serie con las revoluciones socialistas del siglo, sus rasgos fueron intransferibles, más allá del alineamiento de la Cuba de Fidel Castro con la Unión Soviética. El castrismo y el guevarismo tuvieron una vida activa muy breve, aunque intensa, violentamente tronchada por el ciclo de las dictaduras militares latinoamericanas.

Como en Occidente, las décadas de 1970 a 1990 verificaron la caída del ideal revolucionario, y sobre todo de la validez un tanto disminuida de la Revolución Rusa. Fueron décadas de un Geist anti -revolucionario, pesimista y adaptado a las fuerzas del mercado. Un viraje ideológico hacia el escepticismo político y el postmodernismo intelectual creyó decir definitivamente adiós a una noción de revolución recluida en el desván de los trastos inútiles o peligrosos. Cuando en 1994 surgió la novedad zapatista, no reclamó una estatura "revolucionaria" ni quiso exceder los límites de las comunidades chiapanecas. Con la emergencia de los movimientos anti-globalistas, en cambio, se quiso imaginar una revolución postmoderna, fluida y no totalista, contraria a la primacía del poder estatal. En América Latina las consecuencias de esas hipótesis de una revolución de nuevo cuño, postmoderna, no tuvieron demasiadas repercusiones. En todo caso, con el zapatismo la elección de una noción libertaria de "rebelión" quiso librarse de los peligros totalitarios de la revolución.

Las primeras décadas del siglo XXI en América Latina ofrecieron un panorama muy complejo, devastado por las consecuencias de las políticas neoliberales de las décadas de 1980 y 1990. Entonces surgió un ciclo "progresista" de gobiernos "populares", algunos más radicales que otros, entre los que pareció resurgir una política de izquierdas. Los casos venezolano, boliviano y ecuatoriano, 
fueron los más notorios. Las contrariedades que acosaron a las experiencias donde se apeló a algunas formulaciones de "revolución" o incluso "socialismo", todavía no son nítidas pues no han concluido. Lo que puede decirse respecto del tema de este artículo, es que se encuentra ya lejos del ciclo de la Revolución Rusa, cuya relevancia parece muy distante, casi inaudible.

Sin embargo, considerada en una perspectiva de mediana duración, la eficacia simbólica de la Revolución Rusa fue más profunda de lo que su actual desfondamiento sugiere. No solo porque en el pasado marcó la lectura de las experiencias previas de la revolución (por ejemplo en la evaluación del carácter más o menos "burgués" de las revoluciones independentistas), ni porque a pesar de todos los matices fue una presencia relevante en la política latinoamericana entre 1917 y 1960, sino porque en la erradicación de toda contestación revolucionaria por el ciclo de las dictaduras latinoamericanas su amenaza persistió vigente, cuando en realidad en la propia Unión Soviética hacía décadas se había instalado una dictadura burocrática.

En este centenario de la Revolución Rusa en América Latina su sombra parece disgregarse ante las luces del dominio del capital globalizado. Justamente cuando se hace evidente para el sentido común que toda impugnación de una realidad peligrosa e injusta solo puede ser completa, revolucionaria, la promesa más universal de un mundo diferente se pierde en el pasado muerto. Pero nunca se sabe cuál es la posteridad de un acontecimiento que fue un "signo histórico". Tal vez nuevas revoluciones reescriban otras reflexiones donde la Revolución Rusa adquiera un lugar diferente, activo, una sobrevida donde sus ruinas no se disuelvan en la nada sino sean reinscriptas en la lucha interminable por la emancipación. 


\section{REFERENCIAS}

CABALLERO, M. La internacional comunista y la revolución latinoamericana, 1919-1943. Caracas: Nueva Sociedad, 1987.

FALS BORDA, O. Las revoluciones inconclusas en América Latina (1809-1968). México: Siglo Veintiuno, 1970.

FIGES, O. La revolución rusa 1891-1924: la tragedia de un pueblo. Barcelona: Edhasa, 2000.

FLORES GALINDO, A. La agonía de Mariátegui: la polémica con la Komintern. Lima: Desco, 1980.

FORAN, J. (ed.). The Future of Revolutions: Rethinking Radical Change in the Age of Globalization. Londres: Zed Books, 2003.

FURET, F. El pasado de una ilusión: ensayo sobre la idea comunista en el siglo XX. México: Fondo de Cultura Económica, 1995.

GADAMER, H. G. Verdad y método. Salamanca: Sígueme, 1988.

GILLY, A. La revolución interrumpida-México 1910-1920: una guerra campesina por la tierra y el poder. México: El Caballito, 1971.

GRANDIN, G.; JOSEPH, G. M. (eds.). A Century of Revolution: Insurgent and Counterinsurgent Violence during Latin America's Long Cold War. Durham, NC: Duke University Press, 2010.

HALPERIN DONGHI, T. Reforma y disolución de los imperios ibéricos, 1750-1850. Madrid: Alianza, 1985.

HAYA DE LA TORRE, V. R. El antimperialismo y el APRA. Santiago de Chile: Ercilla, 1936.

JAMES, C. L. R. Los jacobinos negros: Toussaint L'Ouverture y la Revolución de Haití. México;Madrid: Fondo de Cultura Económica;Turner, 2003.

JUSTO, L. Bolivia, la revolución derrotada: del Tahuantinsuyu a la insurrección de abril de 1952 y las masacres de mayo y setiembre de 1965 - raíz, proceso y autopsia de la primera revolución proletaria de América Latina. Buenos Aires: Razón y Revolución, 2007.

KNIGHT, A. Social Revolution: a Latin American Perspective. Bulletin of Latin American Research, Medford, MA, v. 9, n. 2, p. 175 - 202, 1990.

KOSELLECK, R. Criterios históricos del concepto moderno de revolución. In: Futuro pasado: para una semántica de los tiempos históricos. Barcelona: Paidós, 1993. p. $67-85$. 
LÖWY, M. El pensamiento del Che Guevara. México: Siglo Veintiuno, 1971.

MARIÁTEGUI, J. C. Siete ensayos de interpretación de la realidad peruana. Caracas: Biblioteca Ayacucho, 1979.

MIRES, F. La rebelión permanente: las revoluciones sociales en América Latina. México: Siglo Veintiuno, 1988.

PIMENTA, J. P. G. Brasil y las revoluciones de Hispanoamérica (1808-1822). In: CALDERÓN, M. T.; THIBAUD, C. (coords.). Las revoluciones del mundo atlántico. Bogotá: Universidad Externado de Colombia-Taurus, 2006.

PITTALUGA, R. Soviets en Buenos Aires. Buenos Aires: Prometeo Libros, 2015.

QUIJANO, A. Introducción a Mariátegui. México: Era, 1982.

RAMOS, J. A. Marxismo para latinoamericanos. Buenos Aires: Plus Ultra, 1973.

ROIO, M. del. A teoria da revolução brasileira: tentativa de particularização de uma revolução burguesa em processo. In: MORAES, J. Q. de; ROIO, M. del (orgs.). História do marxismo no Brasil: Volume IV. Visões do Brasil. Campinas: Editora da Unicamp, 2000. p. 69 - 125.

TARROW, S. El poder en movimiento: los movimientos sociales, la acción colectiva y la política. Madrid: Alianza, 1997.

TROUILlOT, M. R. Silencing the Past: Power and the Production of History. Boston: Beacon Press, 1995.

WILLIAMS, R. Palabras clave: un vocabulario de la cultura y la sociedad. Buenos Aires: Nueva Visión, 2003. 